\title{
Key Components of Modular Propulsion Systems for Next Generation Electric Vehicles
}

\author{
Alexander Stippich, Christoph H. van der Broeck, Alexander Sewergin, Arne Hendrik Wienhausen, \\ Markus Neubert, Philipp Schülting, Silvano Taraborrelli, Hauke van Hoek, and Rik W. De Doncker
}

\begin{abstract}
The objective of this paper is to provide an overview of emerging technologies for modular power converter architectures for electric vehicles. Nowadays, the most common electrical drive-train architecture exhibits one single inverter which is directly tied to the battery. As a consequence, only one high-voltage battery module can be applied and the dc-link voltage of the inverter and its apparent power rating is directly dependent on the available battery voltage. To overcome this restriction, modern power converter architectures with a higher degree of freedom have been proposed. These architectures exhibit modular dc-dc converters to allow different battery technologies to be linked to drive inverters operating independently from each other. To make this development feasible, new components and technologies are evolving which enhance the efficiency over mission cycles while ensuring further integration of the power-converter architectures.

Wide-bandgap power semiconductors enable high switching frequencies and miniaturization of passive devices. Smart topology enhancements and control methods allow a significant loss reduction, in particular at light loads, resulting in a higher efficiency of the drive train over the entire driving cycle. Highly integrated bidirectional battery charger systems with intelligent charging strategies inhibit battery degradation and provide opportunities for grid stabilization. It is demonstrated how these technologies are realized and implemented to contribute to the development of future electric vehicles.
\end{abstract}

Index Terms -Dc-Dc-Converters, drive train, electric vehicles, power electronics, system architecture.

\section{INTRODUCTION}

$\mathrm{T}$ HE unavoidable reduction of green-house gases [1] and the health threatening air pollution in urban areas [2] are major drivers for the extinction of combustion engines and the rise of electric drives as key component for any future transportation. To make this development economically feasible it is necessary to increase efficiency, reduce cost and weight of components and meanwhile improving the overall reliability of the propulsion system.

Nowadays, most electrical drive-train architectures exhibit a single high-voltage battery with more than 100 cells in series

Manuscript received November 22, 2017. This work was supported in part by the German Research Foundation (DFG) as part of the post graduate program mobilEM (GRK 1856), and in part by the German Federal Ministry of Education and Research (BMBF) as part of the project HV-ModAL (16EMO0105) and the project Luftstrom (16EMO0075).

The authors are with the Institute for Power Electronics and Electrical Drives, RWTH Aachen University, Aachen, Germany (e-mail: post@isea. rwth-aachen.de)

Digital Object Identifier 10.24295/CPSSTPEA.2017.00023 resulting into a nominal voltage rating of approximately $400 \mathrm{~V}$ [3]. The high-voltage battery is directly connected to the drive inverter [4], [5]. To enable domestic charging of the battery, a galvanically isolated single-phase unidirectional charger is installed within the vehicle. This architecture has the drawback that the battery voltage and dc-link voltage of the drive inverter are tied to each other. However, the most feasible voltage of the battery pack is not necessarily the perfect voltage for the drive inverter.

From the perspective of the battery pack, a modular and low battery voltage is a desirable design option. It allows to combine high-power and high-energy battery technologies in parallelized units as hybrid battery systems, which promises cost and weight reduction, as well as efficiency improvements in particular under light load conditions [6]-[8]. In addition, battery lifetime can be increased by using a lower battery voltage as this requires fewer cells to be connected in series where the spread in cell aging becomes less relevant [9]. Finally, using modular battery packs at extra low voltages below $60 \mathrm{~V}$ significantly reduces the potential hazards resulting from the battery system during production and maintenance or in case of an accident [8], [10].

In contrast to the battery, the inverter and electric machine can be operated most efficiently at an adjustable dc-link voltage with the aid of dc-to-dc converters [5,] [11], [12]. This is because the switching losses of the inverter can be significantly reduced by dynamic adjustment of the dc-link voltage as function of speed of the machine, which enables lower PWM switching frequencies, lower noise and even transition into six-step operation [13]. The required inverter voltage ranges from the proposed traction battery of, for example, 96 $\mathrm{V}$ to the common dc-link voltage for automotive inverters of $400 \mathrm{~V}$ or even higher. With the introduction of $\mathrm{SiC}$ power modules the dc-link voltage can be raised even higher from $400 \mathrm{~V}$ up to $800 \mathrm{~V}$ [14]. This higher voltage capability increases the power rating of power plugs of charging stations. Consequently, it allows to reduce the charging time of the battery as well as the current rating of the drive train by a factor of two [15]. The possibility to charge faster the battery on the one hand and weight and cost reduction on the other hand are important driving factors, which will continuously push the dc-link voltage of the inverter to the $800 \mathrm{~V}$ level.

Another component within the traditional power architecture, which is worth reconsideration, is the unidirectional charger. In the last years a lot of research has been pursued in the area of bidirectional charger systems typically based on the dual-active bridge (DAB) converter [16]. Bidirection- 


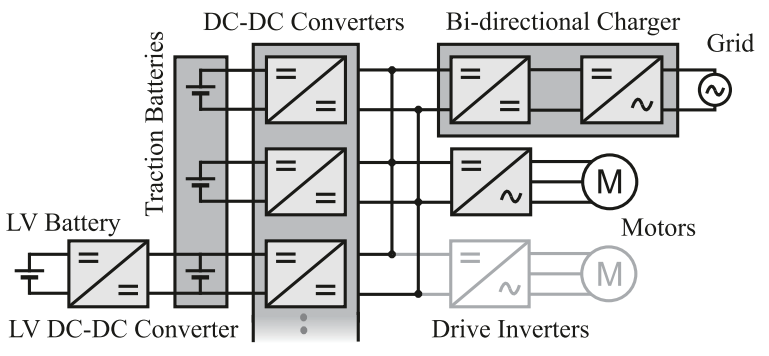

Fig. 1. Modular propulsion system architecture.

al chargers allow to increase the lifetime of batteries with intelligent charging strategies by keeping the state of charge during night at an optimal level [17], [18]. Furthermore, they may support the grid via active and reactive power injection [18]-[20].

The presented arguments underline that a modular power converter architecture exhibiting dc-dc converters as dynamic link between battery units and the drive inverter is a promising solution. The decoupling of the battery voltage from the propulsion system voltae can contribute to a much more efficient operation and lower cost construction of the battery, the inverter and the machine. However, this additional component must pay off, as it adds weight, loss and cost.

This paper addresses the components and operation techniques which are necessary to realize a modular and highly efficient power-converter architecture. The assessment focuses on new devices and components which allow a strong miniaturization and cost reduction of the next generation dcdc converters. Methods for smart loss reduction are presented to increase the efficiency of the proposed architecture in comparison to the traditional one. Finally, technologies for size and loss reduction of a bi-directional battery charger are illustrated.

\section{Next Generation Power Converter Architecture}

The proposed power-converter architecture depicted in Fig. 1 exhibits multiple modular traction batteries. Each battery is connected to a dc link via a dc-dc converter. The dc link supplies one or more drive converters and can be connected directly to the grid using integrated bidirectional battery chargers [18], [21]. The electrical system of the vehicle, which is typically operated at $12 \mathrm{~V}$, is supplied via a low-voltage dc-dc converter connected to one of the traction batteries [22].

This topology has been developed and successfully validated within a full electric vehicle in the publicly funded projects Europahybrid [11] and e performance [23]. The biggest advantage of this propulsion system architecture is its modularity. Standardized battery units with integrated dcdc converters, the so-called smart battery, can be stacked to provide a desired power and energy rating [12], [14]. Thereby, different drive trains can be realized using the same components which results in lower costs due to the economy of scale [5].

In most investigations, the dc-dc converters interfacing the

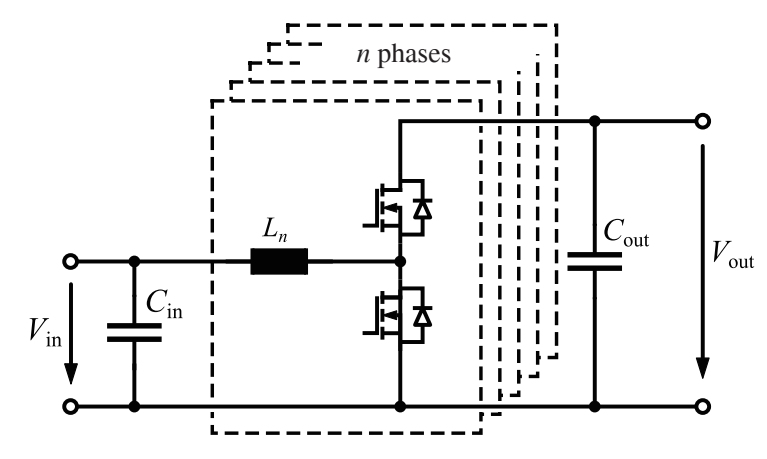

Fig. 2. Multi-phase boost converter.

batteries with the dc link are based on multi-phase boost converters [11], [14], [23]. This topology allows a very efficient and compact design, in particular if wide-bandgap power semiconductors are applied [14], [24]. However, given a rated dc-link voltage of $400 \mathrm{~V}$ the minimal battery voltage cannot be set below $100 \mathrm{~V}$ without jeopardizing the efficiency of the dc-dc converter. For this reason, it is also interesting to consider galvanically isolated topologies with buck-boost functionality, e.g. single or three-phase dual-active bridge (DAB) converters [25]. In case of a galvanic isolation, two $48 \mathrm{~V}$ battery cells can be connected in series to a total of $96 \mathrm{~V}$, with the middle potential tied to the vehicle ground potential like proposed in [5]. Thereby, the entire power converter architecture can rapidly discharge the dc-link bus to ensure that the entire electrical system is intrinsically safe. However, the galvanically isolated converter requires a high-frequency transformer that may add additional losses and weight.

\section{Non-Isolated DC-Dc Converters}

The multi-phase boost converter as shown in Fig. 2 is a promising topology for non-galvanically isolated dc-dc converters which interface a high-voltage battery at, e.g. 400 $\mathrm{V}$, and the drive inverter at a dc-link voltage up to $800 \mathrm{~V}$. It shows high efficiency over the entire output power range when intelligent phase-shifting and phase-shading is applied [14]. Fig. 3 shows a typical efficiency plot for a multi-phase approach with and without phase-shading. Especially at light-load conditions, the efficiency can be increased significantly if a number of phases are turned off corresponding to the required output power. As electric drive trains in EVs are often operated at partial load, the light-load efficiency is an important design criteria of such power converter systems [14].

On the one hand the multi-phase approach is perfectly suited for modular power converters as the output power is scalable by selecting the number of required phases. Furthermore, the parallelization can lead to improved economies of scale.

On the other hand, multiple phases result in higher control complexity and higher costs for additional driver circuitry and sensors. Moreover, the volume occupied by the current sensors and the gate drivers has to be considered. Commercially available gate drivers are often not suitable as they do 


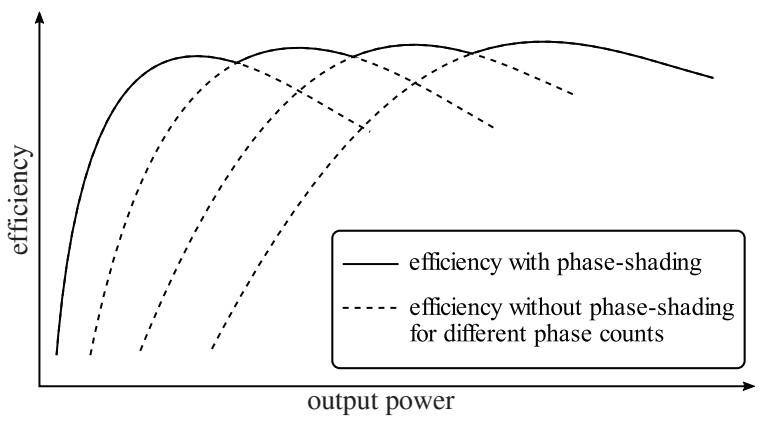

Fig. 3. Typical efficiency plot for multi-phase boost converters with and without phase-shading [14].

not fulfill power density requirements. Therefore, custom and low cost gate drivers have to be designed which fit in the given space.

\section{A. Advantages and Challenges of Wide-Bandgap Devices}

In terms of weight, size and cost, dc-dc-converters for electric vehicles can profit significantly from the application of wide-bandgap (WBG) semiconductors like silicon carbide $(\mathrm{SiC})$ and gallium nitride $(\mathrm{GaN})$. They show superior switching characteristics that allow the designer to raise switching frequencies by at least one decade.

Moreover, all dc-dc converters require passive devices for filters and energy storage. These passive components can be dimensioned smaller with increasing switching frequency, reducing weight, size and cost of the overall system [24], [26]. Despite the higher prices of WBG semiconductors in comparison to silicon semiconductors, the overall system cost in WBG based power converters can be reduced significantly due to the size reduction of passive devices. The smaller the size, the less cost intensive materials like high-performance ferrite, copper or litz-wire are required [24]. In addition, the higher power density results in a reduced weight of the drive train and thus contributes to a higher driving range of EVs.

With increasing switching frequencies the design of passive components, particularly magnetic components, becomes more challenging. Especially in converters with GaN devices, which can operate at elevated $\mathrm{MHz}$ switching frequencies, the magnetic components often enforce a limit on the total power density, because the magnetic losses can not be dissipated easily [26]. To overcome this issue, sophisticated designs of high-frequency magnetic components must be pursued by intensive research [24].

High switching frequencies are also challenging regarding current sensing. Using a multi-phase boost converter, the current of each phase has to be monitored and must be controlled with high bandwidth to ensure a balanced current distribution between all phases. Therefore, current sensors with a high bandwidth are required to sample currents at these elevated switching frequencies. The bandwidth of the current sensors must be at least one decade above the switching frequency of the converter, such that the phase delay between the actual current flowing in the phase and the measured

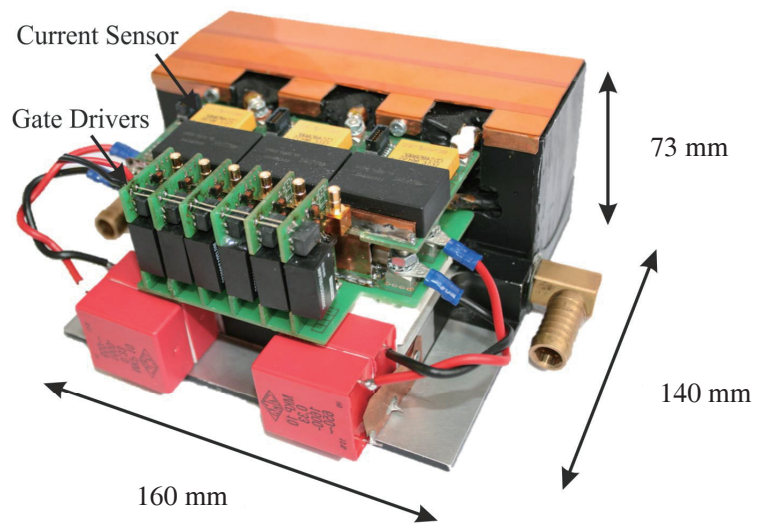

Fig. 4. 3-phase SiC-based boost converter prototype without copper busbars and common mode chokes.

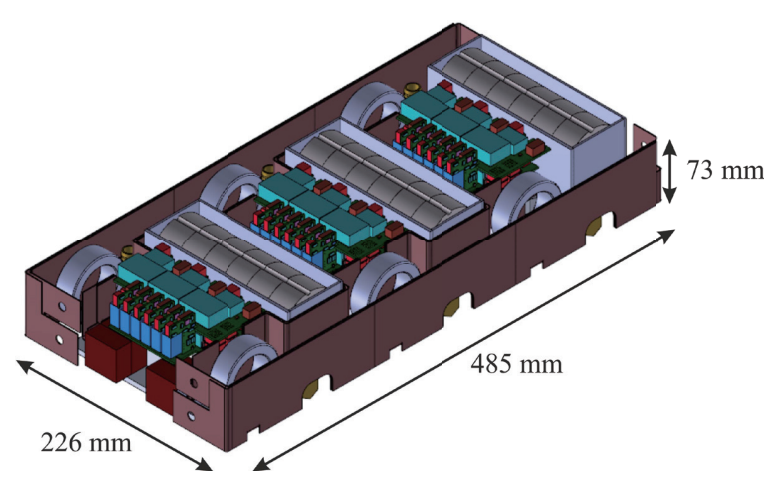

Fig. 5. CAD-model of a 9-phase SiC-based buck-boost converter consisting of 3 converter building blocks, resulting in $126 \mathrm{~kW}$ peak power.

current is minimized. This is important because a large phase delay leads to less time for the processing of the measured data and the computation of the control algorithms.

\section{B. Comparison between Si and SiC based converters}

Fig. 4 gives an example for a compact $\mathrm{SiC}$ dc-dc power-converter building block [14]. It consists of a 3-phase buck-boost converter with a power density of $43 \mathrm{~kW} / \mathrm{dm}^{3}$, a displacement volume of $0.98 \mathrm{dm}^{3}$ and a switching frequency of $150 \mathrm{kHz}$. The main benefit of this dc-dc converter is its modular approach. The converter building block with a peak output power of $42 \mathrm{~kW}$ can be used standalone or in a parallel configuration (see Fig. 5). Thus, the maximum output power is scalable in steps of $42 \mathrm{~kW}$.

The key benefit of SiC-based dc-dc converters becomes obvious in comparison to a representative Si-based converter of the same topology with six phases (see TABLE I). The mentioned Si-based converter with a power density of 6.9 $\mathrm{kW} / \mathrm{dm}^{3}$ and a switching frequency of $16 \mathrm{kHz}$ is shown in Fig. 6. Efficiency measurements of the two dc-dc converters are given in Fig. 7 for a power of up to $42 \mathrm{~kW}$. Both converters, the $\mathrm{Si}$ and the $\mathrm{SiC}$ converter, are operated under hard switching conditions. The switching frequency $f_{\mathrm{sw}}$ of the $\mathrm{SiC}$ converter is nearly a decade higher than of the converter with Si devices. Nevertheless, the overall efficiency 
TABLE I

COMPARISON OF Si AND SiC DC-Dc CONVERTER

\begin{tabular}{lll}
\hline \hline Parameters & Si DC-DC Converter & SiC DC-DC Converter \\
\hline Semiconductor & Si-IGBT $(650 \mathrm{~V})$ & SiC-MOSFET $(1200 \mathrm{~V})$ \\
Power per phase & $40 \mathrm{~kW}$ & $14 \mathrm{~kW}$ \\
$V_{\text {in }}$ & $120-280 \mathrm{~V}$ & $80-500 \mathrm{~V}$ \\
$V_{\text {out }}$ & $\max 400 \mathrm{~V}$ & $\max 900 \mathrm{~V}$ \\
$f_{\text {sw }}$ & $16 \mathrm{kHz}$ & $150 \mathrm{kHz}$ \\
Power density & $6.9 \mathrm{~kW} / \mathrm{dm}^{3}$ & $43 \mathrm{~kW} / \mathrm{dm}^{3}$ \\
\hline
\end{tabular}

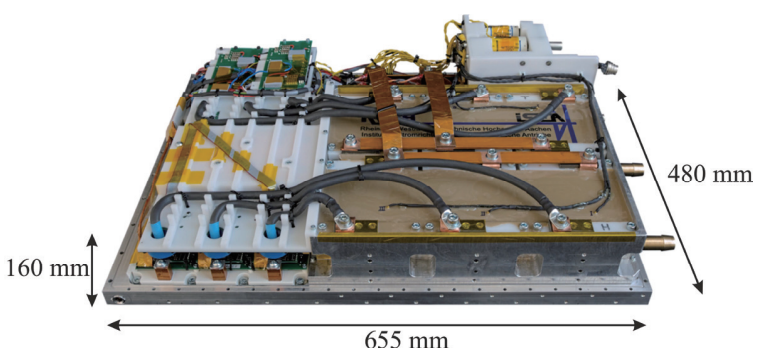

Fig. 6. 6-phase Si-based dc-dc converter with $240 \mathrm{~kW}$ peak power, $35 \mathrm{dm}^{3}$ displacement volume [23]

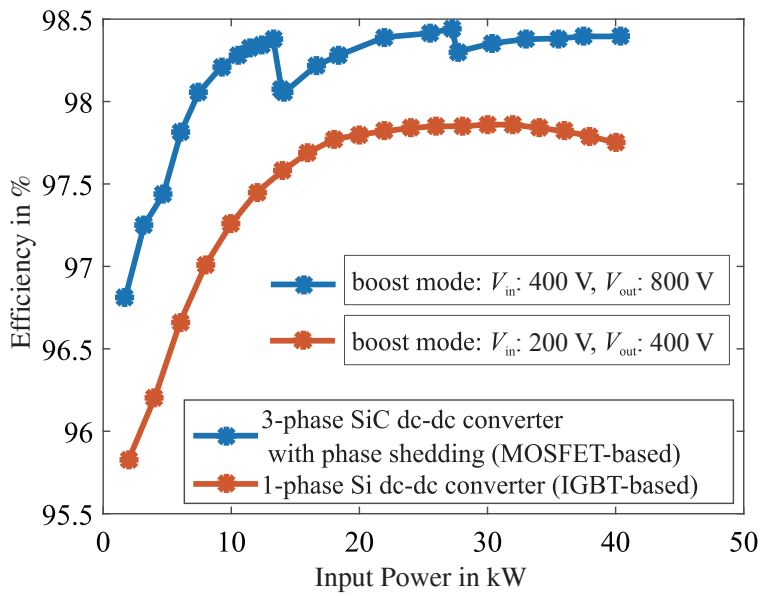

Fig. 7. Efficiency comparison of the 3-phase interleaved $\mathrm{SiC}$ converter building block and 1 phase of the 6-phase Si dc-de converter.

of the $\mathrm{SiC}$ based converter is higher over the whole operating range. The reason is the relatively low switching loss which is inherent to $\mathrm{SiC}$ devices while the more fine-grained phase-shading additionally increases light-load efficiency. The SiC based converter also exhibits a power density increase by a factor of six.

\section{Galvanically Isolated DC-DC Converters}

Galvanically isolated dc-dc converters can be used in different parts of the drive train to realize high voltage conversion ratios or to increase safety. An example for such a converter is the interconnection of the $\mathrm{HV}$ drive train with the $12 \mathrm{~V}$ power system, see Fig. 1. The galvanic isolation is implemented with a high-frequency transformer, which

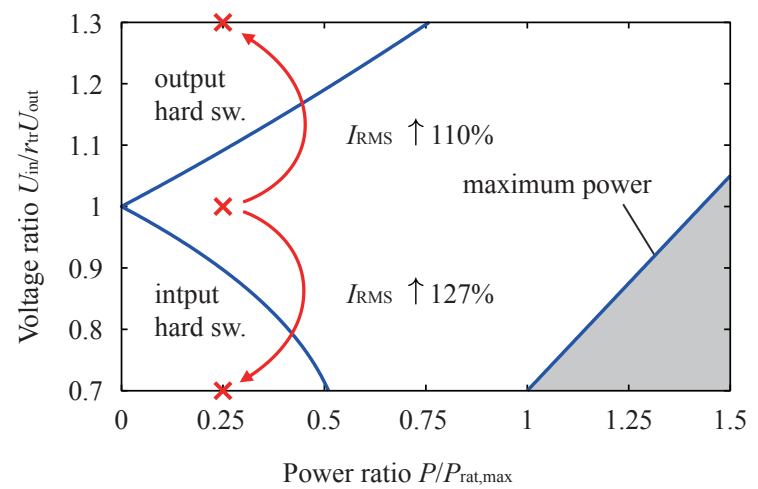

Fig. 8. Exemplary soft-switching boundaries and changes of RMS current of a single-phase DAB converter.

commonly requires a higher effort, particularly more power semiconductors, and a more sophisticated operation scheme compared to a galvanically coupled converter. This brings additional complexity, size, weight and cost to the power converter. Accordingly, efficient and compact converter concepts with high switching frequencies and a carefully designed transformer are essential.

The dual-active bridge converter [25] is one of the most promising galvanically isolated dc-dc converters as it offers a fully bidirectional power transfer, a low number and small size of passive components and a good device utilization [27]. Furthermore, the phase currents and the output currents of the converter can be seamlessly adjusted within less than one switching period resulting in a highly dynamic control of the power flow using a feed-forward control [28], [29].

Dual-active bridge converters are capable of achieving zero-voltage switching (ZVS) over the whole operating range at equal port voltages [25]. Fig. 8 shows typical zero-voltage switching (ZVS) boundaries of a dual-active bridge converter as a function of the voltage ratio and the output power, where $U_{\text {in }}$ is the input voltage, $U_{\text {out }}$ the output voltage, $r_{\text {tr }}$ the transformer turns ratio, $P_{\text {rat,max }}$ the maximum rated power and $I_{\text {rms }}$ the RMS current in the transformer. The boundaries are determined by the design of the converter, i.e., the leakage inductance and the switching frequency, and are strongly influenced by the dead time, the magnetizing current and the output capacitance of the semiconductors [22], [27], [30]. Obviously, the dual-active bridge converter suffers from large hard-switching areas at unequal voltage ratios diminishing the efficiency of the converter. In addition, during hardswitching operation a significant increase of the RMS current in the transformer can be observed, which particularly reduces the efficiency at low to medium powers depending on the covered voltage range [22].

\section{A. Modulation Strategies}

In order to minimize the hard-switching area and the RMS currents of the dual-active bridge converter, sophisticated operation strategies have been developed for the single-phase dual-active bridge [22], [27], [31]. Those so-called 


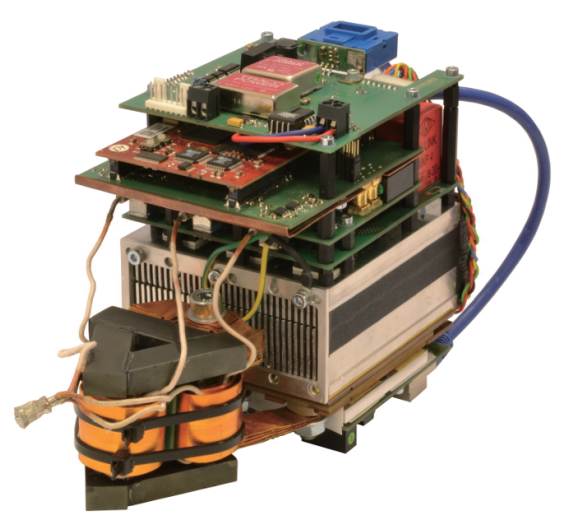

Fig. 9. Photograph of an air-cooled, galvanically isolated three-phase dual-active bridge dc-dc converter. Volume with housing around 2.41.

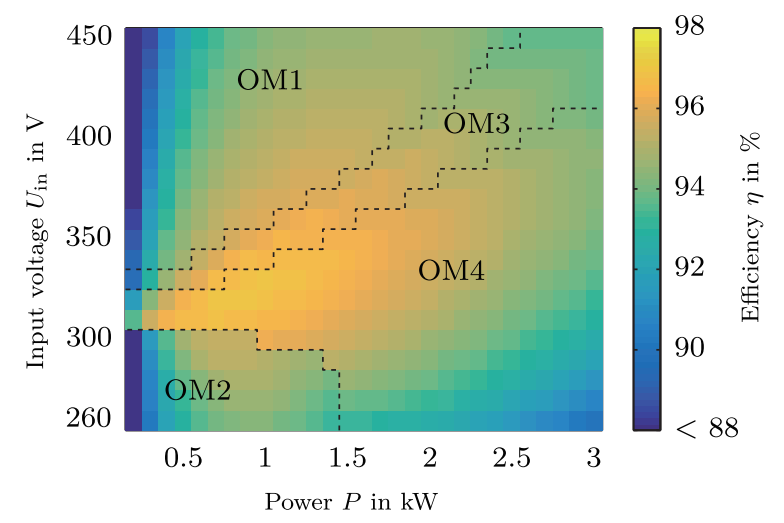

Fig. 10. Efficiency of a three-phase dual-active bridge converter using optimized operation strategies (simulation results).

dual-phase-shift operation strategies utilize the zero-voltage state of the input and output bridges to ensure softswitching over the whole operating range. Among the proposed operation strategies, the triangular and trapezoidal current-mode are most promising as they offer low RMS currents and near zero-current switching over a wide operation range [31]. These operating modes can also be enhanced to achieve zero-voltage switching [22]. This enables converter efficiencies between $90 \%$ and $98 \%$ over a wide voltage and power range.

To further boost maximum efficiency, three-phase dual-active-bridge topologies can be used [31]. Similar to galvanically coupled dc-dc converters, the interleaved operation of multiple phases results in reduced filter size [22]. Multi-phase dual-active bridge converters, however, cannot be operated efficiently over a wide voltage range using the standard single phase-shift operation [25]. Consequently, auxiliary circuits [32] and multilevel topologies have been investigated to improve the soft-switching range and the efficiency [33]. Furthermore, the so-called parallel-phase operation [22], [34], [35] and the duty-cycle operation [36] have been developed. Those operation strategies allow to utilize the dual phase-shift operation strategies known from the single-phase dual-active bridge by either changing the phase shift between the switches of each port or by utilizing

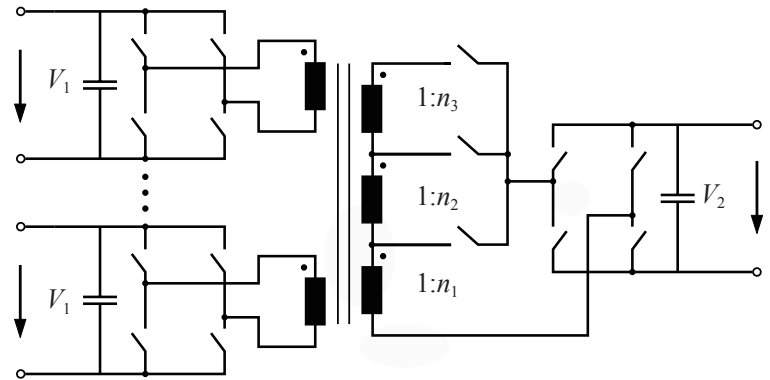

Fig. 11. Dual-active bridge converter with tap changer.

an asymmetric duty cycle. This possibly diminishes some advantages of the multi-phase dual-active-bridges and, therefore, requires a careful design of the converter [22], [35].

Fig. 9 shows the photograph of a highly integrated threephase dual-active bridge dc-dc converter with a rated power of $3 \mathrm{~kW}$ and a switching frequency of $100 \mathrm{kHz}$ [22]. The converter interconnects the low-voltage battery (nominal voltage of $14 \mathrm{~V}$ ) and the high-voltage dc-bus (260 V-450 V), cf. Fig. 1. Despite the galvanic isolation and the low output voltage which results in currents of up to $215 \mathrm{~A}$, measured efficiencies of more than $96 \%$ have been reached [22]. Different operating modes are used (see Fig. 10), which also includes a variation of the switching frequency. Measurements proof that the majority of the operation range can be covered with efficiencies of more than $92 \%$ while a mean efficiency of $93.5 \%$ is reached, which is quite unique given the wide voltage range. The dual-active bridge converter can be easily utilized as a power-electronic building block allowing for easy scalability towards higher powers [27], [37].

\section{B. Dual-Active Bridge Converter with Tap Changer}

The combination of a dual-active bridge converter with a tap changer as outlined in Fig. 11 allows to operate the dual-active bridge converter with high efficiency over an exceptionally wide operating range. This concept has been studied with a single-phase dual-active bridge converter which enables the usage of a low-voltage battery ( $30 \mathrm{~V}$ to 60 $\mathrm{V}$ ) in an HV traction system with a dc-link voltage between $100 \mathrm{~V}$ and $400 \mathrm{~V}$ [38]. This way, the aforementioned improved safety, redundancy and performance of low voltage batteries can be utilized in combination with a variable dclink voltage for higher inverter efficiency.

The transformer with tap changer is introduced to adapt the winding ratio according to the input and output voltages. This enables a converter operation close to unity voltage ratio throughout the whole operating range, which leads to higher efficiencies [38], [39]. Fig. 12 depicts the power losses of a single-phase dual-active bridge converter at different winding ratios $\mathrm{n}$. It can be seen that the power losses at light loads can be significantly reduced when the turn ratios $n=3$ to $n=7$ (cf. Fig. 12(a)-12(c)) are chosen optimally for each operating point (see Fig. 12(d)). This is due to the increased soft-switching area as indicated in Fig. 8 as well the reduced RMS currents. 


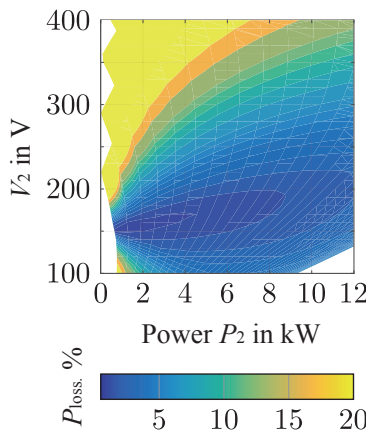

(a) $n=3$

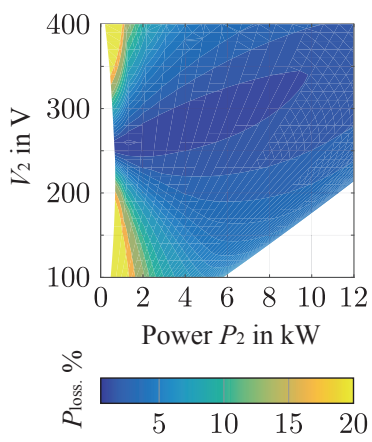

(c) $n=7$

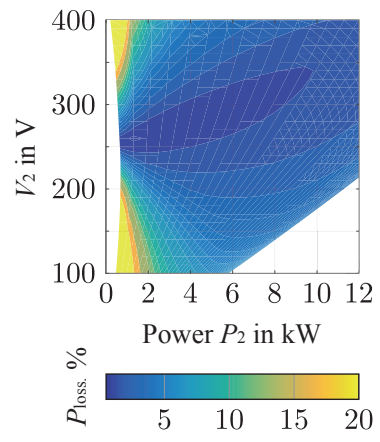

(b) $n=5$

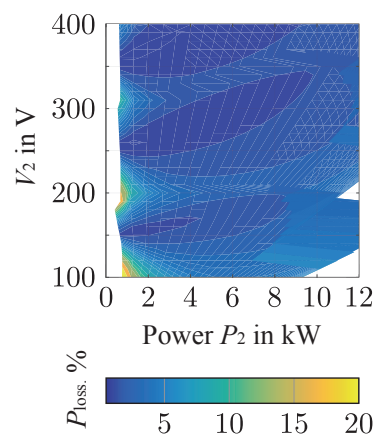

(d) $n=3,5,7$
Fig. 12. Power loss with different tap configurations.

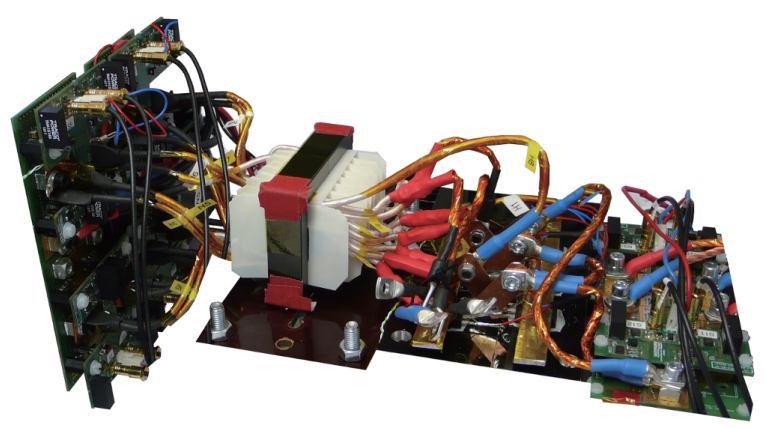

Fig. 13. Photograph of a $10 \mathrm{~kW}$ laboratory prototype of a single-phase dual-active bridge converter with tap changer [38].

Ultimately, the number of taps added to the transformer is a trade-off between efficiency and increased system complexity. Each tap requires additional components to switch between the different taps of the transformer. This can be realized with either relays, thyristors, IGBTs or MOSFETs. The devices must be selected based on the application as each device is a trade-off between cost, size, dynamic behavior and conduction losses of the tap changer. However, remaining hard-switching areas of the converter can still be eliminated by changing the modulation strategy as outlined previously, for example with the triangular modulation.

The design of a transformer with tap changer is more challenging in comparison to the design for a standard transformer of a dual-active bridge converter. The transformer must be coiled with regard to similar stray inductances. Therefore, the magnetic coupling between all windings must be very

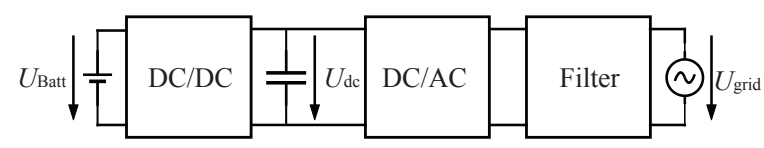

Fig. 14. Topology of a two-stage battery charger.

TABLE II

Measured Efficiency at Different Taps with Turns RATIO $n$ AT $V_{1}=50 \mathrm{~V}$

\begin{tabular}{cccccc}
\hline \hline \multicolumn{2}{c}{$n=3$} & \multicolumn{2}{c}{$n=5$} & \multicolumn{2}{c}{$n=7$} \\
\multicolumn{2}{c}{$V_{2}=150 \mathrm{~V}$} & \multicolumn{2}{c}{$V_{2}=250 \mathrm{~V}$} & \multicolumn{2}{c}{$V_{2}=350 \mathrm{~V}$} \\
$P_{2}$ in $\mathrm{kW}$ & $\eta$ in $\%$ & $P_{2}$ in $\mathrm{kW}$ & $\eta$ in $\%$ & $P_{2}$ in $\mathrm{kW}$ & $\eta$ in $\%$ \\
\hline 0,391 & 93,8 & 0,469 & 94,1 & 0,787 & 96,4 \\
0,745 & 96,4 & 0,839 & 96,8 & 2,316 & 96,4 \\
2,084 & 95,3 & 2,220 & 96,2 & 4,683 & 95,3 \\
3,087 & 94,3 & 3,343 & 95,8 & 5,690 & 94,7 \\
3,975 & 93,1 & 4,373 & 95,0 & 6,660 & 94,2 \\
4,751 & 91,8 & 5,261 & 94,1 & 7,522 & 93,8 \\
& & 6,113 & 93,2 & 8,225 & 92,2 \\
\hline \hline
\end{tabular}

similar to obtain a uniform current distribution between the windings. As a result, the magnetic induction in the ferrite has to be kept relatively low and the transformer has its maximum efficiency at low load and not around the middle of its power range.

Fig. 13 shows an image of a laboratory prototype of a single-phase dual-active bridge converter with a tap changer, a power rating of $10 \mathrm{~kW}$ and a switching frequency of 100 $\mathrm{kHz}$. The low voltage ( $30 \mathrm{~V}$ to $60 \mathrm{~V}$ ) H-bridges can be seen on the left side. To handle the high currents in the LV port and to optimize the current distribution in the transformer, several H-bridges are connected in parallel. Moreover, the presence of multiple H-bridges also allows to connect different battery packs. The transformer and the MOSFET based tap changer are visible in the middle of the photograph. The high-voltage H-bridge which is implemented with $\mathrm{SiC}$ MOSFETs is shown on the right side.

Efficiency measurements of the converter are listed in TABLE II. The converter achieves an efficiency between $91.8 \%$ and $96.8 \%$ using only standard single phase-shift modulation. To further improve the efficiency, more sophisticated modulation strategies like the triangular or trapezoidal modulation mentioned above can be applied.

\section{Grid-Tied Battery Chargers}

In this section, concepts and technology trends for a compact and efficient on-board charging unit are discussed. The most common type of on-board charging systems are single-phase grid-tied chargers that exhibit a power rating of 3.7 $\mathrm{kW}$ to recharge the electric vehicle at any household.

Today, most chargers allow only an unidirectional power flow. Consequently, the battery can be charged from the 


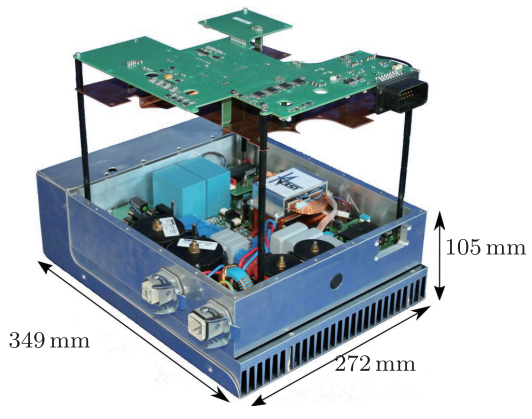

(a) Silicon based charger

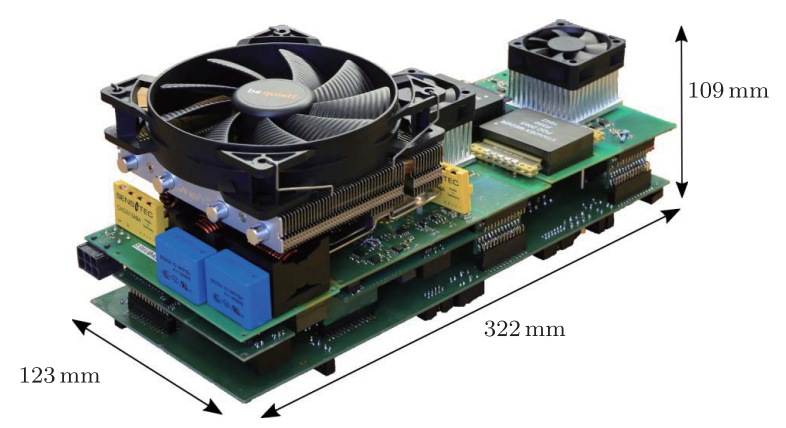

(b) GaN based charger

Fig. 15. Comparison of a Silicon and a GaN based battery charger.

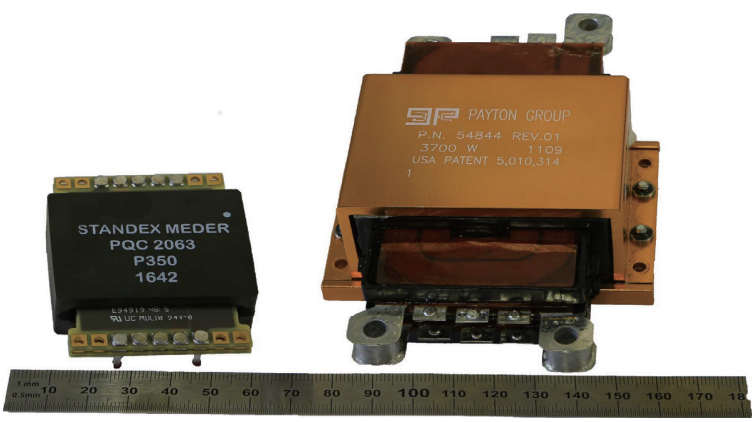

Fig. 16. Comparison of a $500 \mathrm{kHz}$ transformer (left) and a $50 \mathrm{kHz}$ transformer (right) for a power rating of $3.7 \mathrm{~kW}$.

grid but cannot feed energy back into the grid. Bidirectional chargers enable an energy flow in both directions. This can be used to utilize the batteries within the electric vehicles as a large distributed energy storage unit to buffer the fluctuating energy produced by wind and solar power plants, at least, if a significant number of electric vehicles is equipped with such chargers [19]. Furthermore, a bidirectional charger can increase the lifetime of the battery by using intelligent charging strategies which keep the average state of charge (SOC) of the battery at an optimum level during standstill. Despite the increased number of power cycles, the calendaric aging which is directly related to the SOC is significantly reduced and, thus, the lifetime of the battery is enhanced [17], [18].

As the battery charger is commonly implemented inside the electric vehicle, it adds to the overall weight of the vehicle and must be built as small as possible. In case of bidirec-
TABLE III

Dimensions of Both Battery Chargers

\begin{tabular}{cccccc}
\hline \hline & Width & Length & Depth & Volume & Power Density \\
\hline Silicon & $272 \mathrm{~mm}$ & $105 \mathrm{~mm}$ & $349 \mathrm{~mm}$ & 9.91 & $370 \mathrm{w} / 1$ \\
GaN & $123 \mathrm{~mm}$ & $109 \mathrm{~mm}$ & $322 \mathrm{~mm}$ & 4.31 & $860 \mathrm{w} / 1$ \\
\hline \hline
\end{tabular}

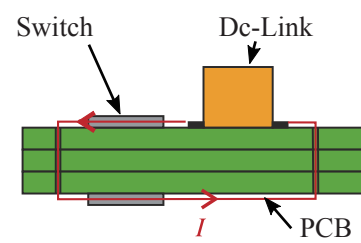

(a) Stray inductance of $3.24 \mathrm{nH}$

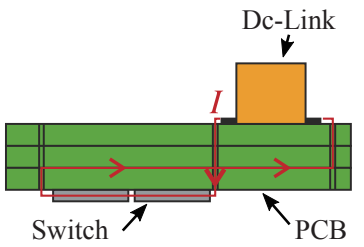

(b) Stray inductance of $2.78 \mathrm{nH}$
Fig. 17. Stray inductances as a result of different layouts.

tional battery chargers, a two-stage topology with a discrete dc link as shown in Fig. 14 is proposed. This way, the inverter tied to the grid and the dc-dc converter connected to the battery can be optimized independently.

The bidirectional dc-dc converter can be realized by a galvanically isolated single-phase dual-active bridge converter, see Section IV. The dc-link capacitor exhibits a power ripple with twice the grid frequency. This power ripple must be buffered by the dc-link capacitor. However, a large capacitor significantly adds to the overall size of the charger [40]. Another solution is to completely apply the power ripple to the battery [41].

\section{A. Battery Charger with Wide-Bandgap Devices}

The advantages and challenges when utilizing GaN devices for battery chargers [42] are quite similar to those outlined in Chapter III-A. For example, passive devices like the transformer of the dual-active bridge converter can be reduced in size and weight. Fig. 16 shows two planar transformers for a switching frequency of $50 \mathrm{kHz}$ and $500 \mathrm{kHz}$ at the same power rating. The size of the transformers are 344 $\mathrm{cm}^{3}$ and $58 \mathrm{~cm}^{3}$, respectively. Due to the increased switching frequency, the volume of the transformer can be reduced by $83 \%$.

The switching frequency of battery chargers, however, is often set below $50 \mathrm{kHz}$ to keep the third harmonic below 150 $\mathrm{kHz}$. As a consequence, the third harmonic of the switching frequency, which cannot be eliminated by choosing sophisticated modulation schemes, does not have to be damped due to CISPR-14 regulation and, thus, eases filtering. However, it was demonstrated, that higher switching frequencies allow to reduce the size of the grid filter components even if the switching frequency itself must be damped. By choosing a switching frequency of $500 \mathrm{kHz}$ the size of the grid filter of a bidirectional charger (cf. Fig. 15(b)) could be reduced by $76.4 \%$. This is because the resonance frequency of the grid filter can be chosen much higher due to the high switching frequency. 
The mentioned GaN based charger with a nominal power of $3.7 \mathrm{~kW}$ and a switching frequency of $500 \mathrm{kHz}$ is depicted in Fig. 15(b). It is air-cooled and has a power density of about 900 W/1. Fig. 15(a) shows a photograph of a Si based battery charger with the same power rating. The corresponding dimensions are listed in TABLE III. The overall volume of the $\mathrm{GaN}$ based charger is lower by 5.61, yielding a power-density increase by a factor of 2.3. This illustrates the miniaturization and integration potential of $\mathrm{GaN}$ devices.

\section{B. Challenges of GaN devices}

At switching frequencies of $500 \mathrm{kHz}$ a careful selection of passive components is important. For example, dc-link film capacitors exhibit a resonant frequency close to the switching frequency and are therefore not suitable. Ceramic capacitors pose a viable alternative.

Furthermore, the layout of the converter board, especially the switching cell, must be designed to achieve low stray inductances in the commutation path, cf. Fig. 17. The package of the GaN devices must also be selected for low stray inductance. At $500 \mathrm{kHz}$, even several $\mathrm{nH}$ of stray inductance will cause high over voltages which increase the switching losses and, hence, limit the switching frequency.

To reduce the switching losses, the switching speed of the GaN devices should be as fast as possible. As a consequence, a high voltage gradient up to $100 \mathrm{kV} / \mu$ s occurs which causes common mode currents in the parasitic capacitances throughout the system. Thus, devices such as the galvanically isolated gate driver must feature minimal coupling capacitances to limit common mode currents.

As the size of GaN devices and packages is considerably smaller than of Si devices, cooling becomes more challenging. Due to the increased heat-flux density, the heat must be dissipated by means of heat spreading. Packages with top-sided cooling allow a direct attachment of heat sinks. Yet, galvanic isolation must be provided, e.g., by a direct copper bonded substrate. Consequently, the substrate can be soldered to the top side of the GaN devices, providing galvanic isolation and heat spreading. A suitable heatsink can then be soldered onto the other side of the substrate to dissipate the heat.

Overall, GaN devices impose new challenges on the design of converter systems. Nevertheless, it is anticipated that they will play a key role to build small yet highly efficient converters for future automotive applications.

\section{Conclusions}

A modular power-electronic architecture for future electric vehicles was proposed which decouples the battery voltage from the dc-link voltage of the machine inverter. The key components of the architecture, namely the dc-dc converters and the battery charger, have been outlined.

If no galvanic isolation is required, multi-phase boost converters in combination with wide-bandgap devices enable small and highly efficient dc-dc converters. For improved safety and reliability, galvanic isolation can be easily included within the architecture. In this case, the dual-active bridge converter is perfectly suited as it provides a bidirectional power flow and requires a minimum amount of additional passive devices. Efficiency issues at lowload conditions have been solved using various approaches. Last but not least, the utilization of bidirectional battery chargers with intelligent charging strategies is endorsed to enhance lifetime of battery cells. In combination with wide-bandgap devices, the size of passive devices including the line filters can be significantly reduced resulting in highly-integrated and efficient battery chargers.

\section{REFERENCES}

[1] Paris agreement, United Nations, 2015.

[2] G. WHO Working Group Bonn, Health aspects of air pollution with particulate matter, Ozone and Nitrogen Dioxide. World Health Organization, Regional Office for Europe, 2003.

[3] S. Rothgang, B. Lunz, I. Laresgoiti et al., "Hv traction battery: From layout to realization," 2012.

[4] S. E. Schulz, "Exploring the high-power inverter: Reviewing critical design elements for electric vehicle applications," IEEE Electrification Magazine, vol. 5, no. 1, pp. 28-35, Mar. 2017.

[5] T. Lange, H. van Hoek, C. Schaeper et al., "Advanced microsystems for automotive applications 2013," in J. Fischer-Wolfarth and G. Meyer, Eds. Springer Science \& Business Media, 2013, ch. Advanced Modular Drive Train Concepts for Electric Vehicles, pp. 223-232.

[6] J. Becker, C. Schaeper, S. Rothgang, et al., "Development and Validation of an Energy Management System for an Electric Vehicle with a split Battery Storage System," Journal of Electrical Engineering \& Technology, vol. 8, no. 4, pp. 920-929, 2013. [Online]. Available: http://publications.rwth-aachen.de/record/239106.

[7] M. Yilmaz and P. T. Krein, "Review of battery charger topologies, charging power levels, and infrastructure for plug-in electric and hybrid vehicles," IEEE Transactions on Power Electronics, vol. 28, no. 5, pp. 2151-2169, May 2013.

[8] S. Rothgang, T. Baumhöfer, H. van Hoek et al., "Modular battery design for reliable, flexible and multitechnology energy storage systems," Applied Energy, vol. 137, pp. 931-937, 2015.

[9] S. Rothgang, T. Baumhöfer, and D. U. Sauer, "Diversion of aging of battery cells in automotive systems," in 2014 IEEE Vehicle Power and Propulsion Conference (VPPC), Oct. 2014, pp. 1-6.

[10] S. Rothgang, H. Nordmann, C. Schäper et al., "Challenges in battery pack design," in 2012 Electrical Systems for Aircraft, Railway and Ship Propulsion, Oct. 2012, pp. 1-6.

[11] T. Schoenen, M. S. Kunter, M. D. Hennen et al., "Advantages of a variable dc-link voltage by using a dc-dc converter in hybrid-electric vehicles," in 2010 IEEE Vehicle Power and Propulsion Conference, Sep. 2010, pp. 1-5.

[12] H. van Hoek, M. Boesing, D. van Treek et al., "Power electronic architectures for electric vehicles," in 2010 Emobility - Electrical Power Train, Nov. 2010, pp. 1-6.

[13] I. Ralev, T. Lange, and R. W. D. Doncker, "Wide speed range six-step mode operation of ipmsm drives with adjustable dc-link voltage," in 2014 17th International Conference on Electrical Machines and Systems (ICEMS), Oct. 2014, pp. 2987-2993.

[14] A. Sewergin, A. H. Wienhausen, K. Oberdieck et al., "Modular bidirectional full-sic dc-dc converter for automotive application," in Accepted for PEDS 2017 in Honolulu, Hawaii, 2017.

[15] C. Jung, "Power up with $800-\mathrm{v}$ systems: The benefits of upgrading voltage power for battery-electric passenger vehicles," IEEE Electrification Magazine, vol. 5, no. 1, pp. 53-58, Mar. 2017.

[16] M. Rosekeit, C. van der Broeck, and R. W. D. Doncker, "Dynamic control of a dual active bridge for bidirectional ac charging," in 2015 IEEE International Conference on Industrial Technology (ICIT), Mar. 2015, pp. 2085-2091. 
[17] B. Lunz, Z. Yan, J. B. Gerschler et al., "Influence of plug-in hybrid electric vehicle charging strategies on charging and battery degradation costs," Energy Policy, vol. 46, pp. 511-519, 2012.

[18] M. Rosekeit, B. Lunz, D. U. Sauer et al., "Bidirektionales ladeger"at f"ur elektrofahrzeuge als energiespeicher im smart grid," 2012.

[19] B. Lunz, T. Pollok, A. Schnettler et al., "Evaluation of battery charging concepts for electric vehicles and plug-in hybrid electric vehicles," in Proceedings of the Ninth International Advanced Automotive Battery \& EC Capacitor Conference, 2009.

[20] R. W. D. Doncker, "Power electronic technologies for flexible dc distribution grids," in 2014 International Power Electronics Conference (IPEC-Hiroshima 2014 - ECCE ASIA), 2014, pp. 736-743.

[21] M. Rosekeit and R. W. D. Doncker, "Galvanically isolated bi directional charger for electric vehicles analysis and implementation," 2011.

[22] H. van Hoek, "Design and operation considerations of three-phase dual active bridge converters for low-power applications with wide voltage ranges," PhD thesis, RWTH Aachen University, Aachen, Germany.

[23] T. Lange, S. Koschik, M. Rosekeit et al., "Forschungsprojekt e performance - modularer systembaukasten f "ur elektrifizierte fahrzeuge," in Allmann, Ed. Cuvillier Verlag, 2013, ch. Leistungselektronik, pp. 221-301.

[24] A. H. Wienhausen, A. Sewergin, and R. W. D. Doncker, "Highly efficient power inductors for high-frequency wide-bandgap power converters," in Accepted for PEDS 2017 in Honolulu, Hawaii.

[25] R. W. A. A. D. Doncker, D. M. Divan, and M. H. Kheraluwala, "A three-phase soft-switched high-powerdensity $\mathrm{dc} / \mathrm{dc}$ converter for high-power applications," IEEE Transactions on Industry Applications, vol. 27, no. 1, pp. 63-73, Jan. 1991.

[26] A. H. Wienhausen and D. Kranzer, "1 mhz resonant dc/dc-converter using 600 v gallium nitride (gan) power transistors," in Silicon Carbide and Related Materials 2012, ser. Materials Science Forum, vol. 740, Trans Tech Publications, Mar. 2013, pp. 1123-1127.

[27] R. Lenke, "A contribution to the design of isolated dc-dc converters for utility applications," Ph.D. thesis, RWTH Aachen University, E.ON Energy Research Center, Institute for Power Generation and Storage Systems (PGS), Germany, 2012.

[28] S. P. Engel, N. Soltau, H. Stagge et al., "Dynamic and balanced control of three-phase high-power dualactive bridge dc-dc converters in dc-grid applications," IEEE Transactions on Power Electronics, vol. 28, no. 4, pp. 1880-1889, Apr. 2013.

[29] S. P. Engel, N. Soltau, H. Stagge et al., "Improved instantaneous current control for high-power three-phase dual-active bridge dc-dc converters," IEEE Transactions on Power Electronics, vol. 29, no. 8 , pp. 4067-4077, Aug. 2014.

[30] N. Soltau, S. P. Engel, H. Stagge et al., "Compensation of asymmetric transformers in high-power dcdc converters," in 2013 IEEE ECCE Asia Downunder, Jun. 2013, pp. 1084-1090.

[31] H. van Hoek, M. Neubert, A. Kroeber et al., "Comparison of a single-phase and a three-phase dual active bridge with low-voltage, high-current output," in Renewable Energy Research and Applications (ICRERA), 2012 International Conference on, Nov. 2012, pp. 1-6.

[32] N. Soltau, J. Lange, M. Stieneker et al., "Ensuring soft-switching operation of a three-phase dual-active bridge dc-dc converter applying an auxiliary resonant-commutated pole," in 2014 16th European Conference on Power Electronics and Applications, Aug. 2014, pp. 1-10.

[33] S. Thomas, "A medium-voltage multi-level de/dc converter with high voltage transformation ration," Ph.D. thesis, RWTH Aachen University, Aachen, Germany, 2013.

[34] H. van Hoek, M. Neubert, and R. W. D. Doncker, "Enhanced modulation strategy for a three-phase dual active bridge: Boosting efficiency of an electric vehicle converter," IEEE Transactions on Power Electronics, vol. 28, no. 12, pp. 5499-5507, Dec. 2013.

[35] H. van Hoek, K. Jacobs, M. Neubert et al., "Enhanced operating strategy for a three-phase dual-active-bridge converter including frequency variation," in 11th International Conference on Power Electronics and Drive Systems (PEDS), Sydney, Australia, Jun. 2015, pp. 492-498.

[36] J. Hu, N. Soltau, and R. W. D. Doncker, "Asymmetrical duty-cycle control of three-phase dual-active bridge converter for soft-switching range extension," in 2016 IEEE Energy Conversion Congress and
Exposition (ECCE), Sep. 2016, pp. 1-8.

[37] N. Soltau, "High-power medium-voltage dc-dc converters: Design, control and demonstration," Ph.D. thesis, RWTH Aachen University, Aachen, German, 2017.

[38] S. Taraborrelli, R. Spenke, and R. W. D. Doncker, "Bidirectional dual active bridge converter using a tap changer for extended voltage ranges," in 2016 18th European Conference on Power Electronics and Applications (EPE'16 ECCE Europe), Sep. 2016, pp. 1-10.

[39] M. Stieneker and D. De, "Dc-to-dc converter comprising a transformer," WO Patent App. PCT/EP2015/066,788, Jan. 2016.

[40] M. Rosekeit and R. W. D. Doncker, "Smoothing power ripple in single phase chargers at minimized dc-link capacitance," in 8th International Conference on Power Electronics - ECCE Asia, May 2011, pp. 2699-2703.

[41] R. Prasad, C. Namuduri, and P. Kollmeyer, "Onboard unidirectional automotive g2v battery charger using sine charging and its effect on li-ion batteries," in 2015 IEEE Energy Conversion Congress and Exposition (ECCE), Sep. 2015, pp. 6299-6305.

[42] P. Schuelting, D. Kubon, and R. W. D. Doncker, "Electrical design considerations for a $4 \mathrm{kw}$ buck converter with normally-off gan devices at a dc-link voltage of $400 \mathrm{v}$," in 2016 IEEE 2nd Annual Southern Power Electronics Conference (SPEC), Dec. 2016, pp. 1-6.

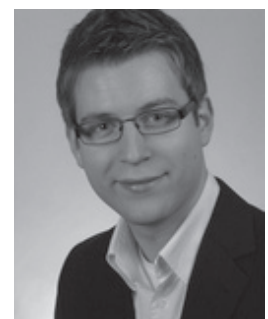

Alexander Stippich received the B. Sc. and M. Sc. degree in electrical engineering and M.Sc. degree in Business and Economics from RWTH Aachen University, Aachen, Germany, in 2012, 2014 and 2015, respectively. Since November 2015, he has been with the Institute for Power Electronics and Electrical Drives (ISEA), RWTH Aachen University, where he is currently research assiocate in the power electronics group. His main research focus is on the packaging of wide bandgap semiconductor devices and power

electronic systems.

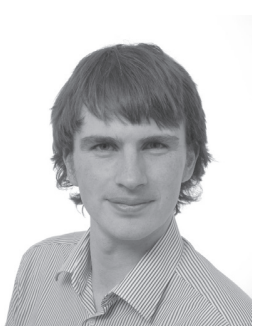

Christoph H. van der Broeck received the B. Sc. and M. Sc. degree in electrical engineering from RWTH Aachen University, Germany, in 2010 and 2013. From 2011 to 2012 he joined the Wisconsin Electric Machine and Power Electronic Consortium at the University of Wisconsin, Madison, as a Fulbright Scholar. Between 2012 and 2013 he worked with AixControl $\mathrm{GmbH}$ on control design of power converters. Since January 2014, he has been working towards the Ph.D. degree at the Institute for Power Electronics and Electrical Drives (ISEA), RWTH Aachen University. His research interests include the modeling and control of power electronic converters and drives.

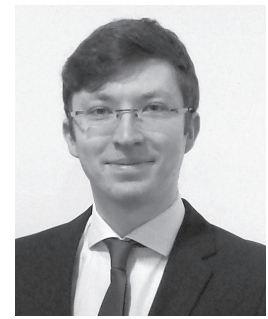

Alexander Sewergin received the B.Sc. and M.Sc. degrees in electrical engineering from RWTH Aachen University, Aachen, Germany, in 2012 and 2015, respectively. Since May 2015 he has been a Research Associate with the Institute for Power Electronics and Electrical Drives (ISEA) at RWTH Aachen University. His research interests include widebandgap based power converters and modular power converter applications for electric vehicles. 


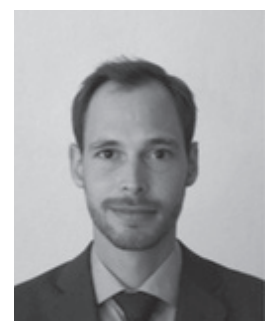

Arne Hendrik Wienhausen received his diploma degree in electrical engineering from RWTH Aachen University, Germany, in 2012. After his studies he joined the power electronics department of the Fraunhofer Institute for Solar Energy Systems ISE, Freiburg, Germany. Since 2016 he is with the Institute for Power Electronics and Electrical Drives (ISEA), RWTH Aachen University, as a group leader of the power electronics group. His main research focus is on the application of wide bandgap devices for high-frequency power electronics and on high-speed signal processing.

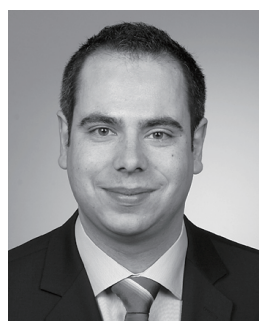

Markus Neubert received the Diploma degree in electrical engineering from RWTH Aachen University, Aachen, Germany, in 2012. Since October 2012, he has been with the Institute for Power Electronics and Electrical Drives (ISEA), RWTH Aachen University, where he is currently team leader of the power electronics group. His research interests are in the field of power electronics and control.

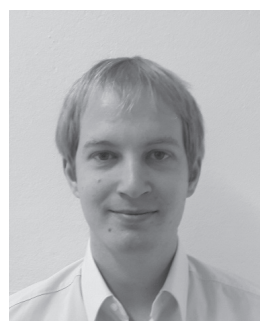

Philipp Schülting received the B.Sc and M.Sc degrees in electrical engineering from RWTH Aachen University, Aachen, Germany, in 2014. Since January 2015, he has been with the Institute for Power Electronics and Electrical Drives (ISEA), RWTH Aachen University. His research interests are in the field of power electronics and control.

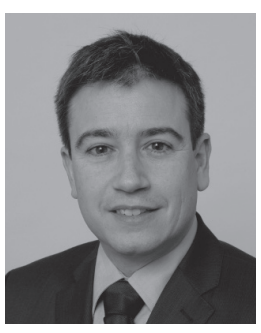

Silvano Taraborrelli received the Diploma degree in electrical engineering from the Politecnico di Torino, Italy, in 2010. Since January 2012 he is working as research assistant at the Institute for Power Electronics and Electrical Drives (ISEA), RWHT Aachen University, Germany. His research interest are in the field of power electronics, in particular for DC-DC converters for automotive applications.

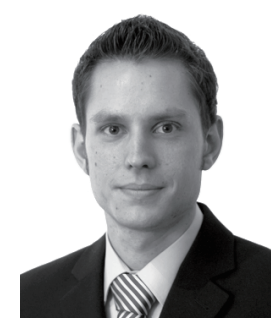

Hauke van Hoek received the Diploma degree in electrical engineering from RWTH Aachen University, Aachen, Germany, in 2009. Since August 2009 he has been a research associate with the Institute for Power Electronics and Electrical Drives (ISEA) at RWTH Aachen University, where he is chief engineer since 2015. His research interests are in the field of powerelectronic circuits for low and medium power applications, in particular for electric vehicles.

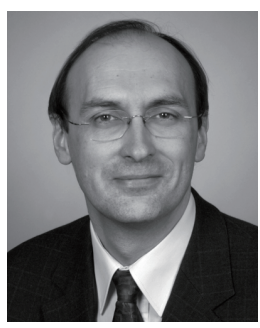

Rik W. De Doncker received the Ph.D. degree in electrical engineering from the Katholieke Universiteit Leuven, Leuven, Belgium, in 1986. In 1987, he was appointed Visiting Associate Professor at the University of Wisconsin, Madison. After a short stay as an Adjunct Researcher with IMEC, Leuven, he joined, in 1989, the Corporate Research and Development Center, General Electric Company, Schenectady, NY. In 1994, he joined Silicon Power Corporation, a former division of General Electric Inc., as Vice President of Technology. He is currently a Professor at RWTH Aachen University, Germany, where he leads the Institute for Power Electronics and Electrical Drives. In 2006, he also became Director of the E.ON Energy Research Center, RWTH Aachen University. Dr. De Doncker was the President of the IEEE Power Electronics Society (PELS) in 2005 and 2006. He was founding Chairman of the German IEEE Industry Applications Society (IAS) PELS Joint Chapter. In 2002, he was recipient of the IAS Outstanding Achievement Award. In 2008, he received the IEEE Power and Energy Society Nari Hongorani Custom Power Award. In 2009, he led a VDE/ETG Task Force on Electric Vehicles. In 2010, he received a honorary doctor degree of TU Riga, Latvia. In 2010, he became member of the German National Platform for Electromobility. 